\title{
Factors associated with failure of bony union after conservative treatment of acute cases of unilateral lumbar spondylolysis
}

\author{
Masaki Tatsumura $^{1 *}$ D, Hisanori Gamada ${ }^{2}$ D, Shun Okuwaki ${ }^{2}$, Fumihiko Eto ${ }^{1}$, Katsuya Nagashima ${ }^{1}$ (D)
} Takeshi Ogawa ${ }^{1}$, Takeo Mammoto ${ }^{1}$ (D) Atsushi Hirano ${ }^{1}$, Masao Koda ${ }^{2}$ (D) and Masashi Yamazaki ${ }^{2}$ (D)

\begin{abstract}
Background: If bone union is expected, conservative treatment is generally selected for lumbar spondylolysis. However, sometimes conservative treatments are unsuccessful. We sought to determine the factors associated with failure of bony union in acute unilateral lumbar spondylolysis with bone marrow edema including contralateral pseudarthrosis.

Methods: This study targeted unilateral lumbar spondylolysis treated conservatively in high school or younger students. Conservative therapy was continued until the bone marrow edema disappeared on MRI and bone union was investigated by CT. We conducted a univariate analysis of sex, age, pathological stage, lesion level complicating the contralateral bone defect, lesion level, and intercurrent spina bifida occulta, and variables with $p<0.1$ were considered in a logistic regression analysis. An item with $p<0.05$ was defined as a factor associated with failure of bony union.

Results: We found 92 cases of unilateral spondylolysis with bone marrow edema and 66 cases were successfully treated conservatively. Failure of bony union in unilateral lumbar spondylolysis with bone marrow edema was associated with progressive pathological stage $(p=0.004)$, contralateral pseudarthrosis $(p<0.001)$, and L5 lesion level $(p=0.002)$. The odds ratio was 20.0 (95\% Cl 3.0-193.9) for progressive pathological stage, 78.8 (95\% Cl 13-846) for contralateral pseudarthrosis, and 175 (95\% Cl 8.5-8192) for L5 lesion level.

Conclusions: Conservative therapy aiming at bony union is contraindicated in cases of acute unilateral spondylolysis when the pathological stage is progressive, the lesion level is $L 5$, or there is contralateral pseudarthrotic spondylolysis.
\end{abstract}

Keywords: Lumbar spondylolysis, Union inhibitor, Contralateral pseudarthrosis lesion, Treatment failure and risk factor

\footnotetext{
* Correspondence: tatsumura@md.tsukuba.ac.jp

${ }^{1}$ Department of Orthopaedic Surgery and Sports Medicine, Tsukuba

University Hospital Mito Clinical Education and Training Center, Mito Kyodo

General Hospital, 3-2-7 Miyamachi, 310-0015 Mito, Ibaraki, Japan

Full list of author information is available at the end of the article
}

C The Author(s). 2021 Open Access This article is licensed under a Creative Commons Attribution 4.0 International License, which permits use, sharing, adaptation, distribution and reproduction in any medium or format, as long as you give appropriate credit to the original author(s) and the source, provide a link to the Creative Commons licence, and indicate if changes were made. The images or other third party material in this article are included in the article's Creative Commons licence, unless indicated otherwise in a credit line to the material. If material is not included in the article's Creative Commons licence and your intended use is not permitted by statutory regulation or exceeds the permitted use, you will need to obtain permission directly from the copyright holder. To view a copy of this licence, visit http://creativecommons.org/licenses/by/4.0/. The Creative Commons Public Domain Dedication waiver (http://creativecommons.org/publicdomain/zero/1.0/) applies to the data made available in this article, unless otherwise stated in a credit line to the data. 


\section{Background}

Lumbar spondylolysis is a fatigue fracture of pars interarticularis, most of which occur in the 5th lumbar spinal vertebra (L5) [1]. It often occurs in athletes and adolescents and can be fused by conservative treatment [2]. The union rate of lumbar spondylolysis is lower than that of general fatigue fractures. A wide variation in union rate has been reported: $87 \%$ in early stage spondylolysis [2], and $<56 \%$ despite treatment for up to 6 months or more [3]. A possible reason for the substantial variation in union rate between the reports is that there are multiple confounding factors that have a significant impact on bone union. Previous reports revealed several possible factors affecting bone union after conservative treatments for lumbar spondylolysis, including vertebral level [4], stage [4], contralateral condition [4], bilateral spondylolysis [5], and latent spina bifida [6, 7]. Contralateral pseudarthrosis might be an inhibitory factor for bony union because new spondylolysis tends to occur when a bone defect occurs on the opposite side of the vertebral arch [8]. However, the precise influence of contralateral pseudarthrosis on bony union rate remains to be elucidated.

Treatment strategies for lumbar spondylolisthesis are controversial. Especially for unilateral surgical treatment, it has been reported that surgery is desirable when symptoms persist for 6 months or longer [9]. In addition, even when surgical treatment is selected, if unilateral pars cleft is present, the surgical results are better than bilateral [10]. On the other hand, if bone fusion can be expected, conservative treatment is also an option. Where bony union cannot be expected by conservative therapy, symptomatic therapy or surgical therapy should be considered rather than continuing exercise or depriving patients of exercise opportunities. Therefore, it is necessary to establish a prognosis of bony union at the time of initial diagnosis of patients with lumbar spondylolysis to determine the treatment strategy. We sought to elucidate the major factors associated with failure of bony union in acute unilateral lumbar spondylolysis with bone marrow edema including contralateral pseudarthrosis.

\section{Patients and methods}

\section{Patients}

This study targeted patients with lumbar spondylolysis, which was treated conservatively in our institute from 2014 to 2019. We extracted data from cases in high school students and younger children who were diagnosed with fresh unilateral spondylolysis with bone marrow edema by MRI at the first visit. We excluded cases in which acute lumbar spondylolysis
Table 1 Patient demographics

\begin{tabular}{ll}
\hline Patient Demographics $(\boldsymbol{n}=\mathbf{9 2})$ & \\
\hline Treatment Result & 66 \\
Union & 26 \\
Pseudoarthrosis & \\
Sex & 72 \\
Male & 20 \\
Female & 14.4 (9-18) \\
Age at First Visit (years old) & \\
Pathological Stage & 21 \\
Prelysis & 50 \\
Early & 21 \\
Progressive & \\
Contralateral Condition & 67 \\
Normal & 25 \\
Bone defect & \\
Vertebral Level of The Lesion & \\
L3 & 94 \\
L4 & \\
L5 & 19 \\
Intercurrent SBO & 64 \\
With & \\
\hline
\end{tabular}

occurred on both sides, and cases in patients who did not consent to conservative therapy.

\section{Methods}

Conservative therapy included using a rigid brace, stopping exercising (including physical class at their school) and physiotherapy until the bone marrow edema disappeared as seen by MRI. Bony union as evaluated with reconstructed sagittal and axial CT images at the time of disappearance of bone marrow edema was the primary outcome of the present study. Failure of bony union was defined as bone incontinuity in reconstructed sagittal and axial CT images.

To determine the factors significantly associated with failure of bony union, we conducted a univariate analysis with bony union at the final visit as the dependent

Table 2 Univariate analysis

\begin{tabular}{ll}
\hline Univariate analysis & $\boldsymbol{p}$-value $(\# \mathbf{p}<\mathbf{0 . 1})$ \\
\hline Age & 0.4 \\
Sex & 0.85 \\
L5 or non-L5 & $0.001 \#$ \\
Spina Bifida Occulta & 0.2 \\
CT Prgoressive Stage & $<0.001 \#$ \\
Contralateral Pseudarthrosis & $<0.001 \#$ \\
\hline
\end{tabular}


Table 3 Stepwise Logistic Regression

\begin{tabular}{lll}
\hline Stepwise Logistic Regression & $\boldsymbol{p}$-value $\left(^{*}: \boldsymbol{p}<\mathbf{0 . 0 5}\right)$ & odds ratio $(\mathbf{9 5 \%}$ Cl) \\
\hline L5 or non-L5 & $0.002^{*}$ & $175(8.5-8192)$ \\
CT Prgressive Stage & $0.004^{*}$ & $20.0(3.0-193.9)$ \\
Contralateral Pseudarthrosis & $<0.001^{*}$ & $78.8(13-846)$ \\
\hline
\end{tabular}

variable and the following items as independent variables: sex, age, pathological stage of spondylolysis in the axial plane of CT [11], contralateral pseudarthrosis, lesion level, and spina bifida occulta. The disease stage was classified as progressive or not (prelysis and early stage) and the level of pathology was separated into L5 and non-L5. Variables with $p<0.1$ were included in logistic regression analysis (forward-backward stepwise selection method). Any item with $p<0.05$ was defined as a factor associated with bony union failure.

\section{Result}

We included data from 92 patients with cases of unilateral spondylolysis on MRI. Successful bony union was achieved in 66 patients after conservative treatment and the remaining 26 patients failed to obtain bony union, which was diagnosed as pseudarthrosis. The patients included 72 boys and 20 girls with an average age of
14.4 (range 9-18) years. A prelysis stage was found in 21 patients, early stage was found in 50, and progressive stage in 21. Contralateral pseudarthrosis was found in 25 patients, whereas no pseudarthrosis was found in the remaining 67 . The level of spondylolytic lesion was L3 in 9 patients, L4 in 19, and L5 in 64 (Table 1). There were 54 patients with spina bifida occulta.

Univariate analysis revealed that progressive pathological stage $(p<0.001)$, contralateral pseudarthrosis $(p<0.001)$, and L5 lesion level $(p=0.001)$ were significantly associated with bony union failure, whereas age $(p=0.40)$, sex $(p=0.85)$, and spina bifida occulta $(p=$ 0.20 ) were not (Table 2). The 3 factors showing $p<0.1$ in univariate analysis were then analyzed using logistic regression with a forward-backward stepwise selection method. The logistic regression revealed that progressive pathological stage $(p=0.004$, odds ratio (OR) $20.0 ; 95 \%$ CI 3.0-193.9), L5 lesion level ( $p=0.002$, OR 175; 95\% CI

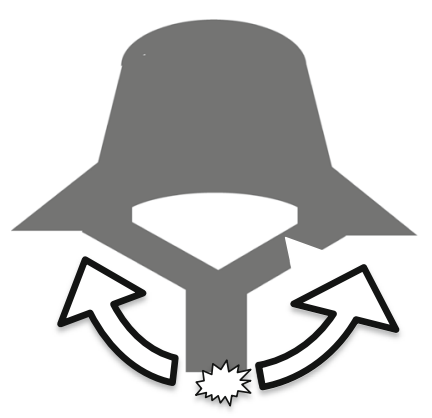

a) mechanical stress with contralateral normal

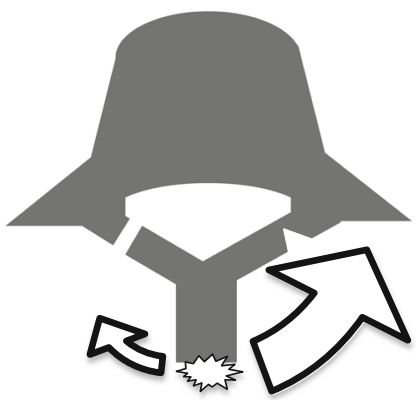

b) mechanical stress with contralateral pseudoarthrosis

Fig. 1 The direction and magnitude of the mechanical load are indicated by arrows. a In the normal case without contralateral spondylolysis, the mechanical stress from the posterior is evenly distributed to the left and right vertebral arches. $\mathbf{b}$ When a bone defect occurs due to terminal stage spondylolysis, the mechanical stress from the posterior is concentrated at the site of acute spondylolysis where bone continuity remains. Therefore, stability is not attained and the union rate is low 
8.5-8192) and contralateral pseudarthrosis $(p<0.001$, OR 78.8; 95\% CI 13-846) (Table 3) were significantly associated with failure of bony union.

\section{Discussion}

In the present study, we found that lesion level (L5), pathological stage, and contralateral pseudarthrosis were significantly associated with failure of bone union in patients with acute unilateral lumbar spondylolysis and bone marrow edema.

L5 is the most frequent lesion level for lumbar spondylolysis [12]. The union rate of L5 lesions is lower than that for other levels $[13,14]$. In the present study, we also found that the union rate at the vertebral level of L5 was significantly lower than that for other vertebral levels. The progressive stage of the disease was previously reported to have a significant negative impact on bony union [15], because according to the stage of disease progression a larger bony defect occurs, which may inhibit bony union.

In addition to the abovementioned known factors that have a significant negative impact on bony union after conservative therapy for lumbar spondylolysis, we demonstrated that unilateral lumbar spondylolysis with contralateral pseudarthrosis is a major risk factor for bony union failure, with an odds ratio of 78.8. Mechanical load can increase significantly when there is pseudarthrosis on the contralateral side of the vertebral arch, resulting in the development of additional fresh spondylolysis $[8,16]$. Because contralateral pseudarthrosis disrupts the bone continuity of the vertebral arch, bony union of fresh spondylolysis may be inhibited by the concentration of stress, possibly resulting in a lower rate of bony union (Fig. 1).

In the case of fatigue fractures of the extremities, delayed treatment can lead to bony union failure, resulting in a poor prognosis. Therefore, early surgery is indicated according to the prognosis of the stress fractures related to the site and/or stage of the fracture. Surgery may also be considered for stress fractures to shorten rest period and hasten the return to the sports, although they can be healed by conservative treatment. This principal can be indicated for lumbar spondylolysis. As is widely known, conservative treatment is the first choice for fresh lumbar spondylolysis associated with bone marrow edema, and surgery might be considered only when low back pain persists $[9,17]$.

According to the present results, conservative therapy aimed at bony union should not be applied automatically to all cases. Conservative therapy for acute unilateral spondylolysis should be considered carefully and the patients fully informed of risk factors for bony union failure including progerssive stage, a lesion level at L5, and contralateral pseudarthrosis. In such cases, an option is to conduct symptomatic treatment without prolonged external fixation and rest, without aiming for bony union. Another option is to perform direct surgical repair to avoid long rest for attaining bony union earlier.

The limitation of this study is that detailed clinical findings of each case such as the degree of pain could not be confirmed. In addition, it is a retrospective survey and the details of the case where the treatment was dropped out could not be confirmed.

\section{Conclusions}

Conservative therapy aiming at bony union is contraindicated in cases of acute unilateral spondylolysis when the pathological stage is progressive, the lesion level is L5, or there is contralateral pseudarthrotic spondylolysis.

\section{Abbreviation \\ L5: the 5th lumbar spinal vertebra}

\section{Acknowledgements}

Not applicable.

\section{Authors' contributions}

MT conceived and designed the study. HG and SO collated and analyzed the data. FE, KN, TO, TM and AH treated the patients. MT, HG and MK drafted the manuscript. MY critically revised the draft manuscript. All the authors approved the final version submitted for publication.

\section{Funding}

None.

\section{Availability of data and materials}

The datasets generated during and analyzed during the current study are available from the corresponding author on reasonable request.

\section{Ethics approval and consent to participate}

All procedures including review of patient record used in this research were approved by the institutional review board of Tsukuba University Hospital Mito Clinical Education and Training Center/ Mito Kyodo General Hospital (No.17-01). Verbal informed consents were obtained from all patients and their parent to participate in this study. An IRB approve the study and the procedure outlined for the verbal consent obtainment.

\section{Consent for publication}

Written informed consent for publication was obtained from the patients included in this study.

\section{Competing interests}

The authors declare that there are no relevant competing interest.

\section{Author details}

${ }^{1}$ Department of Orthopaedic Surgery and Sports Medicine, Tsukuba University Hospital Mito Clinical Education and Training Center, Mito Kyodo General Hospital, 3-2-7 Miyamachi, 310-0015 Mito, Ibaraki, Japan.

${ }^{2}$ Department of Orthopaedic Surgery, Faculty of Medicine, University of Tsukuba, Tsukuba, Japan.

Received: 16 June 2020 Accepted: 30 December 2020

Published online: 13 January 2021

\section{References}

1. Sakai T, Sairyo K, Suzue N, Kosaka H, Yasui N. Incidence and etiology of lumbar spondylolysis: review of the literature. J Orthop Sci. 2010;15:281-8. 
2. Sairyo K, Sakai T, Yasui N. Conservative treatment of lumbar spondylolysis in childhood and adolescence: the radiological signs which predict healing. J Bone Joint Surg Br. 2009;91:206-9.

3. Dunn AJ, Campbell RS, Mayor PE, Rees D. Radiological findings and healing patterns of incomplete stress fractures of the pars interarticularis. Skeletal Radiol. 2008;37:443-50.

4. Fujii K, Katoh S, Sairyo K, Ikata T, Yasui N. Union of defects in the pars interarticularis of the lumbar spine in children and adolescents: the radiological outcome after conservative treatment. J Bone Joint Surg Br. 2004;86:225-31.

5. Morita T, Ikata T, Katoh S, Miyake R. Lumbar spondylolysis in children and adolescents. J Bone Joint Surg Br. 1995;77:620-5.

6. Yamamoto T, linuma N, Miyamoto K, Sugiyama S, Nozawa S, Hosoe H, Shimizu K. Segmental wire fixation for lumbar spondylolysis associated with spina bifida occulta. Arch Orthop Traum Surg. 2008:128:1177-82.

7. Quah C, Yeoman MS, Cizinauskas A, Cooper KC, Peirce NS, McNally DS, Boszczyk BM. Finite element investigation of the effect of a bifid arch on loading of the vertebral isthmus. Spine J. 2014;14:675-82.

8. Sairyo K, Katoh S, Sasa T, Yasui N, Goel VK, Vadapalli S, Masuda A, Biyani A, Ebraheim N. Athletes with unilateral spondylolysis are at risk of stress fracture at the contralateral pedicle and pars interarticularis: a clinical and biomechanical study. Am J Sports Med. 2005:33:583-90

9. Debnath UK, Freeman BJ, Grevitt MP, Sithole J, Scammell BE, Webb JK Clinical outcome of symptomatic unilateral stress injuries of the lumbar pars interarticularis. Spine (Phila Pa 1976). 2007;32:995-1000

10. Debnath UK, Scammell BE, Freeman BJC, McConnell JR. Predictive factors for the outcome of surgical treatment of lumbar spondylolysis in young sporting individuals. Global Spine J. 2018:8:121-8.

11. Tatsumura M, Gamada H, Ishimoto Ryu, Okuwaki S, Eto F, Ogawa T, Mammoto T, Hirano A. Prevalence of curable and pseudoarthrosis stages of adolescent lumbar spondylolysis. J Rural Med. 2018;13:105-9.

12. Scemama C, Magrino B, Gillet P, Guigui P. Risk of adjacent-segment disease requiring surgery after short lumbar fusion: results of the French spine surgery society series. J Neurosurg Spine. 2016;25:46-51.

13. Yu CH, Lee JE, Yang JJ, Chang BS, Lee CK. Adjacent segment degeneration after single-level PLIF: comparison between spondylolytic spondylolisthesis, degenerative spondylolisthesis and spinal stenosis. Asian Spine J. 2011;5:8290.

14. Goda Y, Sakai T, Sakamaki T, Takata Y, Higashino K, Sairyo K. Analysis of MRI signal changes in the adjacent pedicle of adolescent patients with fresh lumbar spondylolysis. Eur Spine J. 2014;23:1892-5.

15. Sakai T, Tezuka F, Yamashita K, Takata Y, Higashino K, Nagamachi A, Sairyo K. Conservative treatment for bony healing in pediatric lumbar spondylolysis. Spine. 2017:42:E716-20.

16. Inceoğlu S, Mageswaran P. Multi-scale finite element modelling at the posterior lumbar vertebra: analysis of pedicle stresses due to pars fracture. Comput Methods Biomech Biomed Engin. 2014;17:787-91.

17. Nachemson A. Repair of the spondylolisthesic defect and intertransverse fusion for young patients. Clin Orthop Relat Res. 1976;117:101-5.

\section{Publisher's Note}

Springer Nature remains neutral with regard to jurisdictional claims in published maps and institutional affiliations.

Ready to submit your research? Choose BMC and benefit from:

- fast, convenient online submission

- thorough peer review by experienced researchers in your field

- rapid publication on acceptance

- support for research data, including large and complex data types

- gold Open Access which fosters wider collaboration and increased citations

- maximum visibility for your research: over $100 \mathrm{M}$ website views per year

At BMC, research is always in progress.

Learn more biomedcentral.com/submissions 